\title{
Chimney and sandwich stent grafts for hybrid repair of type A dissection late after a Bentall for Marfan syndrome
}

Hong-wei Zhang, MD, Kang-jun Fan, MD, Huai-min Liang, MD, and Jia Hu, MD, PhD, Chengdu, People's Republic of China

\footnotetext{
From the Department of Cardiovascular Surgery, West China Hospital, Sichuan University, Chengdu, Sichuan, People's Republic of China.

This study was supported in part by the National Natural Science Foundation of China (No. 81300155).

Drs Zhang, Fan, and Liang contributed equally to the study.

Disclosures: Authors have nothing to disclose with regard to commercial support.

Received for publication Feb 20, 2016; revisions received April 4, 2016; accepted for publication April 23, 2016; available ahead of print May 17, 2016.

Address for reprints: Jia Hu, MD, PhD, Department of Cardiovascular Surgery, West China Hospital, Sichuan University, Guo Xue Alley 37\#, Chengdu, Sichuan, People's Republic of China, 610041 (E-mail: humanjia@msn.com).

J Thorac Cardiovasc Surg 2016;152:1191-3

$0022-5223 / \$ 36.00$

Copyright (C) 2016 by The American Association for Thoracic Surgery

http://dx.doi.org/10.1016/j.jtcvs.2016.04.071
}

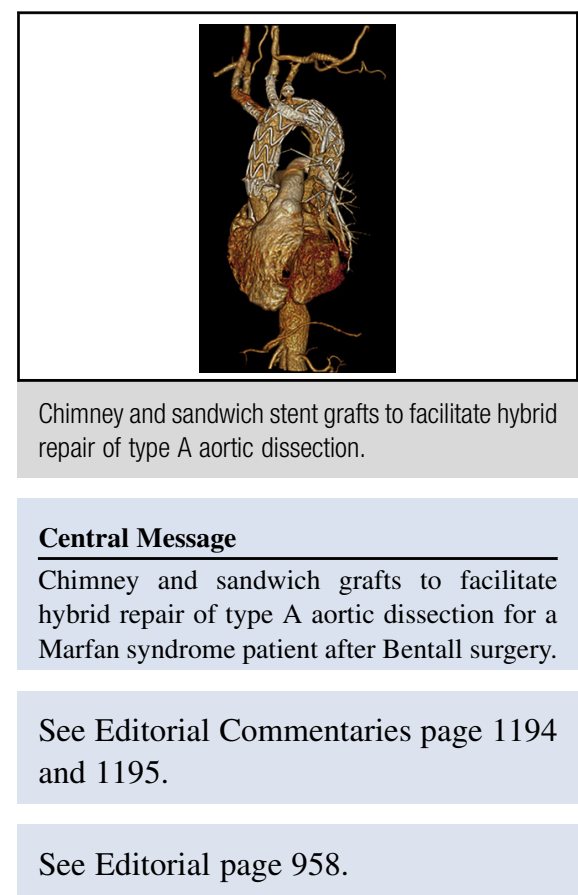

Because of patient's refusal to undergo reopen surgery and a complex repeated surgical setting with high risk, a less-invasive hybrid treatment strategy was accepted as reasonable by interdisciplinary consensus. First, a LCCA-left axillar artery bypass was created with $6 \mathrm{~mm}$ of Gore-Tex graft (W. L. Gore and Associates, Newark, Del), lead through the costoclavicular passage. Then, the first (distal) thoracic stent graft (red, tapered $28 \mathrm{~mm}$ $24 \mathrm{~mm} \times 15 \mathrm{~cm}$; Valiant Captiva, Medtronic, Minneapolis, Minn) was introduced from the right femoral artery and deployed at the proximal descending aorta. The second (proximal) thoracic stent graft (blue, straight $34 \mathrm{~mm} \times 15 \mathrm{~cm}$, Valiant Captiva; Medtronic) was inserted into the previous ascending synthetic graft. As the chimney grafts, two $10 \mathrm{~mm} \times 80 \mathrm{~mm}$ Fluency Plus covered stents (green; Bard Peripheral Vascular, Tempe, Ariz) were delivered from the right brachial and innominate artery into the ascending graft. Another 2 Fluency grafts (yellow, $12 \mathrm{~mm} \times 80 \mathrm{~mm} ; 10 \mathrm{~mm} \times 80 \mathrm{~mm}$ ) were delivered from the LCCA into the endolumen of the first (distal) thoracic stent graft.

After the second (proximal) thoracic stent graft was deployed successfully at the intended position, the 


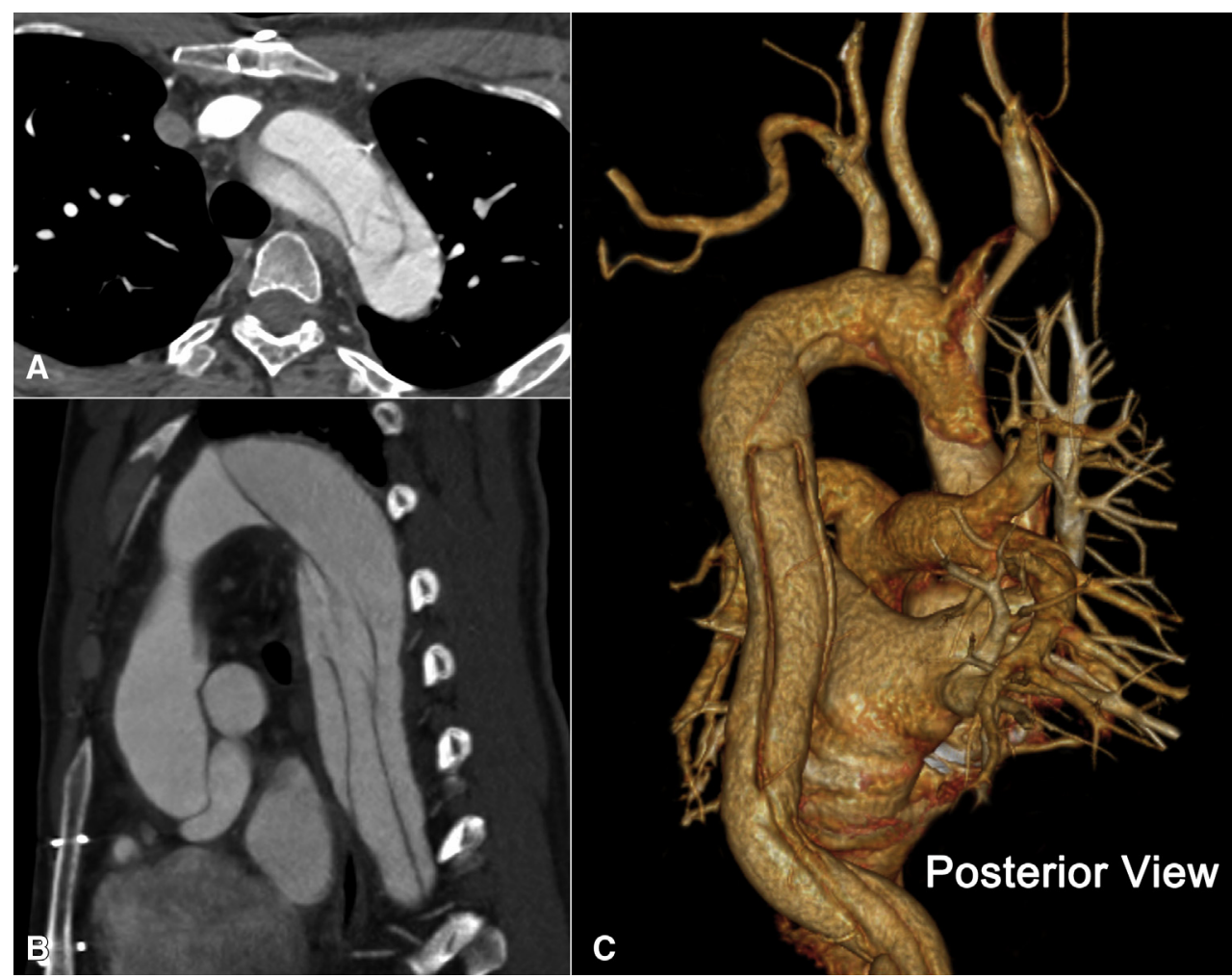

FIGURE 1. Preoperative, A, transverse, B, sagittal, and C, 3-dimensional volume-rendered computed tomography angiography demonstrating the type A aortic dissection with a primary entry tear at the arch.

precisely positioned stent grafts from the innominate artery and the LCCA were deployed, and the covered stents for the LCCA was sandwiched between the 2 thoracic stent grafts (Figure 2, A). The left subclavian artery was occluded by a 10 -mm double-disk vascular occluder. On the angiography at completion, we

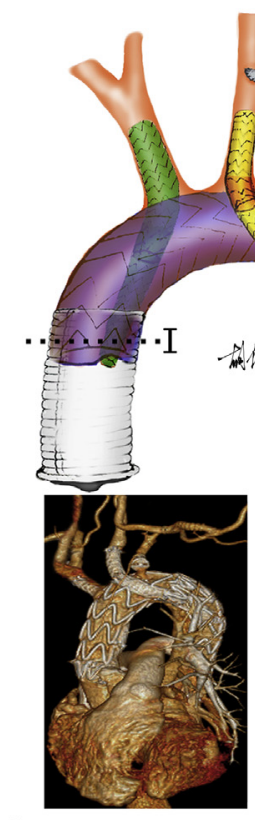

A
5 POD
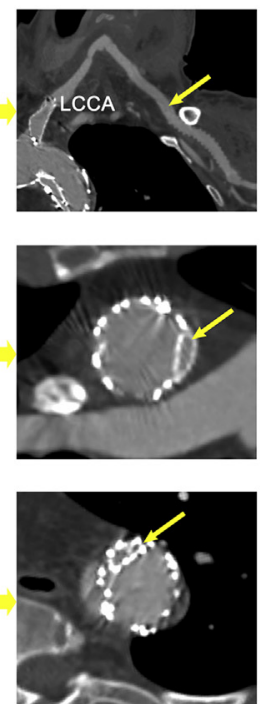

30 POD
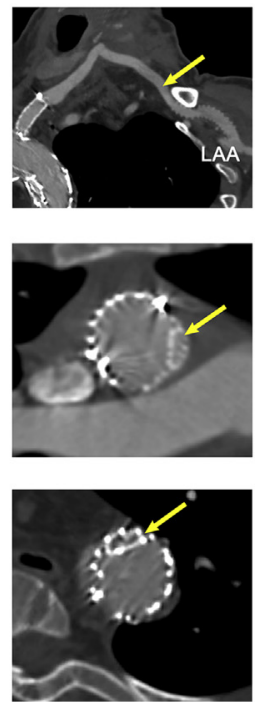

B

FIGURE 2. A, The diagram of hybrid arch repair and chimney/sandwich techniques: I, proximal transverse section; II, distal transverse section; red, the distal thoracic stent graft; blue, the proximal thoracic stent graft; green, the chimney stent graft; yellow, the sandwich stent graft. B, Postoperative computed tomography angiography of 5 days and 30 days showing complete sealing of the primary entry tear with patent chimney, sandwich, and LCCA-LAA bypass grafts (Gore-Tex). POD, Postoperative days; $L C C A$, left common carotid artery; $L A A$, left axillary artery. 


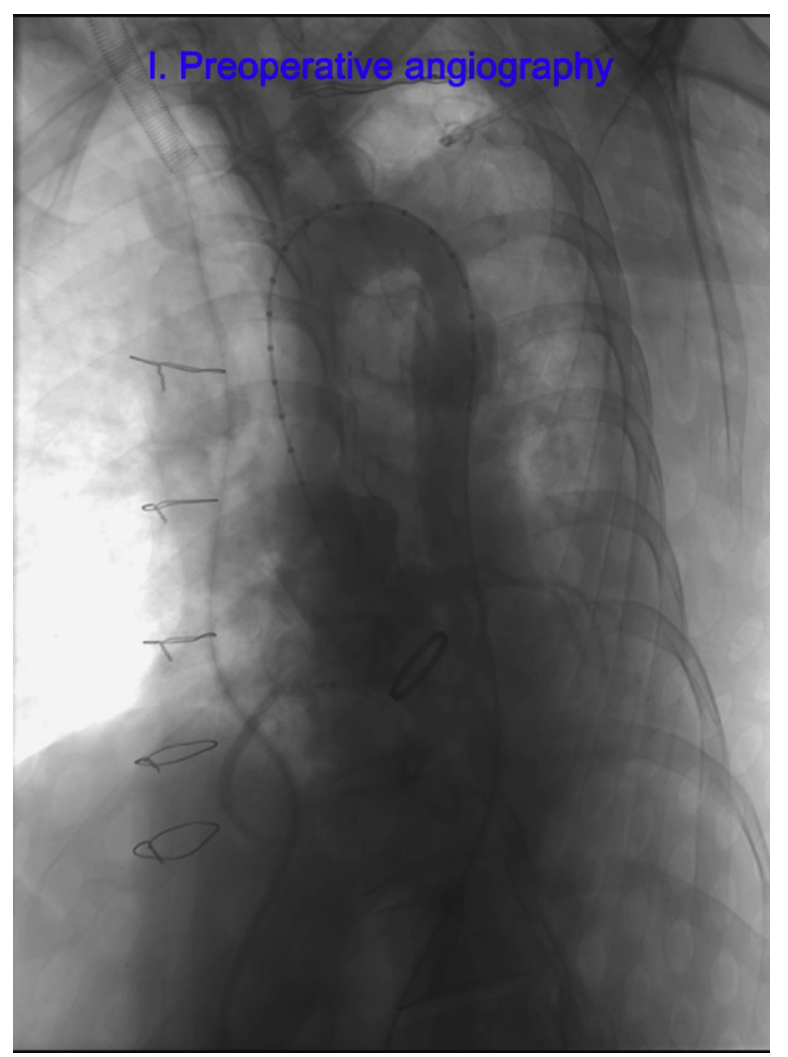

VIDEO 1. The procedures of hybrid arch repair and chimney/sandwich techniques. Video available at http://www.jtcvsonline.org.

recognized a type III endoleak from the overlap zones between the 2 thoracic stent grafts (Video 1). The postoperative course was uneventful, and predischarge CTA 5 days after surgery showed complete sealing of the primary entry tear with patent chimney and sandwich grafts. At 30 days follow-up, the patient was asymptomatic, and CTA confirmed the patency of the supra-arch grafts (Figure 2, B).

\section{DISCUSSION}

An endovascular solution for patients with MFS remains controversial because of its limited durability and high risk of stent graft-related complications and reinterventions. ${ }^{3,4}$ In our patient, the proximal and distal landing zones for the second (proximal) thoracic stent graft and the intraaortic landing zones for the chimney and sandwich grafts were within prostheses, which would decrease the risk of possible injury to the fragile aortic wall exerted by the radial force of stent grafts. In addition, endoleaks after thoracic endovascular aortic repair with 1 or more supra-arch endoprostheses are common, with a reported occurrence of $11 \%-30 \%$, and most were handled conservatively. ${ }^{5}$ Our patient also presented with a persisted type III endoleak 30 days after surgery; however, no signs of arch aneurysmal enlargement and any exacerbation of the endoleak were observed.

A carotid-to-carotid bypass grafting might be an alternative to limit the number of parallel stent grafts for decreasing the risk of endoleaks in this case; however, we used 2 supra-arch endoprostheses because of the dissection of the proximal innominate artery and LCCA and the concern of the long-term patency of a carotid-to-carotid bypass. Life-long imaging surveillance is mandatory, and future coil embolization might be a reliable option for the endoleaks. To our knowledge, this is the first reported case of a hybrid treatment for new-onset, type A aortic dissection in patients with MFS with a previous Bentall procedure. Although further staged repairs are required in our case, this endovascular technique could be an effective and life-saving treatment option for high-risk repeated surgical patients with MFS.

The authors acknowledge Dr Yang Li for his assistance in figure preparation.

\section{References}

1. Kari FA, Beyersdorf F, Stephens EH, Peter P, Rylski B, Russe M, et al. Results after thoracic aortic reoperations in Marfan syndrome. Ann Thorac Surg. 2014;97: 1275-80.

2. Vallabhajosyula P, Szeto WY. Current paradigms in aortic arch repair: striking the balance between open surgery and endovascular repair. J Thorac Cardiovasc Surg. 2015; 150:1399-400.

3. Roselli EE, Idrees JJ, Lowry AM, Masabni K, Soltesz EG, Johnston DR, et al Beyond the aortic root: staged open and endovascular repair of arch and descending aorta in patients with connective tissue disorders. Ann Thorac Surg. 2016;101: 906-12.

4. Gagné-Loranger M, Voisine P, Dagenais F. Should endovascular therapy be considered for patients with connective tissue disorder? Can J Cardiol. 2016;32:1-3.

5. Lindblad B, Bin Jabr A, Holst J, Malina M. Chimney grafts in aortic stent grafting: hazardous or useful technique? Systematic review of current data. Eur J Vasc Endovasc Surg. 2015;50:722-31. 